\title{
Diagnostic Utility of Impedance-pH Monitoring in Refractory Non-erosive Reflux Disease
}

\author{
Mohammed Q Khan, ${ }^{*}$ Ali Alaraj, Fahad Alsohaibani, Khalid Al-Kahtani, Sahar Jbarah and Hamad Al-Ashgar \\ Section of Gastroenterology, Department of Medicine, King Faisal Specialist Hospital and Research Center, Riyadh, Saudi Arabia
}

\begin{abstract}
Background/Aims
Approximately one-third of non-erosive reflux disease (NERD) patients are refractory to proton pump inhibitors (PPI) and face a therapeutic challenge. Therefore, it is important to differentiate between pathological and non-pathological reflux utilizing multichannel intraluminal impedance-pH (MII-pH) to analyze symptom-reflux association and diagnose true NERD versus hypersensitive esophagus (HE) and functional heartburn (FH). Herein, we evaluated the diagnostic yield of MII-pH in refractory NERD and sub-classified it based on quantity and quality of acid/non-acid reflux and reflux-symptom association.
\end{abstract}

\section{Methods}

Sixty symptomatic NERD patients on twice daily PPI for $>2$ months were prospectively evaluated by MII-pH. Distal and proximal refluxes, bolus exposure time (BET), esophageal acid exposure time, symptom index (SI) and symptom association probability (SAP) were measured.

\section{Results}

Thirty-two (53\%) patients had BET > 1.4\% (MII-pH positive-true NERD), while $28(47 \%)$ had BET $<1.4 \%$ (MII-pH negative NERD) where SI and SAP were negative in 15/60 (25\%; categorized as FH) and SI or SAP were positive in 13/60 (22\%; identified as HE). Thirty-eight $(63 \%)$ patients reported significant SI or SAP parameters where $>80 \%$ of symptoms were associated with non-acid reflux. The number of distal refluxes in true NERD versus FH or HE were significantly different, but not between $\mathrm{FH}$ and $\mathrm{HE}$.

\section{Conclusions}

Approximately $60 \%$ of refractory PPI NERD patients had positive reflux-symptom association, primarily due to non-acid reflux. Nearly half of NERD patients on PPI had normal MII-pH monitoring, sub-divided further into FH and HE equally.

\section{(J Neurogastroenterol Motil 2014;20:497-505)}

\section{Key Words}

Impedance-pH monitoring; Non-erosive reflux disease; Refractory NERD

Received: April 2, 2014 Revised: June 17, 2014 Accepted: June 18, 2014

(C) This is an Open Access article distributed under the terms of the Creative Commons Attribution Non-Commercial License (http://creativecommons. org/licenses/by-nc/3.0) which permits unrestricted non-commercial use, distribution, and reproduction in any medium, provided the original work is properly cited.

*Correspondence: Mohammed Q Khan, MRCP (UK)

Section of Gastroenterology, Department of Medicine (MBC-46), KFSH \& RC, P.O. Box 3354, Riyadh 11211, Saudi Arabia

Tel: +966-501001495, Fax: +966-114427499, E-mail: mohamedkhan@kfshrc.edu.sa

Financial support: None.

Conflicts of interest: None.

Author contributions: Mohammed Q Khan performed the Impedance-pH monitoring, Esophageal HRM and wrote the paper; Ali Alaraj and Fahad Alsohaibani collected the data and compiled the data sheet; Khalid Al-Kahtani, Hamad Al-Ashgar and Fahad Alsohaibani performed the esophagogastroduodenoscopy; Sahar Jbarah helped in conducting the procedure of impedance-pH monitoring; Hamad Al-Ashgar supervised the whole project.

ORCID: Mohammed Q Khan, http://orcid.org/0000-0002-6966-2550. 


\section{Introduction}

Recent studies documented that up to $70 \%$ of reflux patients have typical symptoms in the absence of endoscopically visible esophageal mucosal injuries, making non-erosive reflux disease (NERD) a more common form of gastroesophageal reflux disease (GERD). ${ }^{1}$ Currently, the most common GERD treatment is with a proton pump inhibitor (PPI), but there are reported cases in which this treatment fails, especially among NERD patients. A comprehensive definition of PPI refractoriness was proposed recently: "persistence of GERD symptoms after 8 weeks of appropriate and correctly performed PPI treatment at standard doses." ${ }^{2}$ A large American Gastroenterology Association survey found that despite PPI use, over $55 \%$ of GERD subjects (mixed erosive and non-erosive diseases) remained symptomatic. ${ }^{3}$ The PPI pooled response rate found to be significantly higher in erosive reflux disease (56\%) relative to NERD patients $(37 \%){ }^{4}$ Although heartburn was most commonly linked to acid reflux, it was also produced by non-acid reflux, while regurgitation was unchanged by acid suppression, being generally triggered by non-acid reflux. After PPI therapy, the percentage of acid reflux decreased from $45 \%$ to $3 \%$, while non-acid reflux increased from $55 \%$ to $97 \%{ }^{5}$

The advent of multichannel intraluminal impedance-pH monitoring (MII-pH) has represented a major advance in the diagnosis and management of GERD. It is currently emerging as the new "gold standard" for clarifying differences in PPI refractory symptoms. MII-pH monitoring allows detection of acidic, weakly acidic and weakly alkaline refluxes as well as differentiates liquid, gas and mixed refluxes, which is now considered to be the best detection method to characterize GERD, but the nature of the refluxate; bile or pepsin cannot be determined by this method. ${ }^{6}$ Savarino et $\mathrm{al}^{7}$ have proposed a sub-classification of NERD patients incorporated on the basis of MII-pH and symptom association probability (SAP) results as follows: (1) $\mathrm{pH}$-positive NERD - abnormal distal esophageal acid exposure time (EAET), (2) hypersensitive esophagus (HE) - normal EAET and positive symptom association for either acid and/or non-acid reflux and (3) functional heartburn (FH) - normal EAET and negative symptom association. The $\mathrm{FH}$ sub-classification is clinically important as NERD patients show better response to acid-suppressive therapy, while those with $\mathrm{FH}$ have a negligible response and are more likely to have an accompanying psychopathology.
A recent study has reported the advantage of MII-pH monitoring in refractory GERD over conventional pH studies.' Unfortunately, there are few prospective MII-pH trials on PPI-refractory NERD patients. The objective of our study was to evaluate the usefulness of MII-pH monitoring in PPI-refractory NERD in order to differentiate between pathological and functional heartburn by identifying and correlating the nature of acid or non-acid reflux with associated symptoms, which would help clinicians to decide an appropriate therapeutic option for each sub-class of NERD.

\section{Materials and Methods}

\section{Patients}

Permission to conduct this study was obtained from the research advisory committee and research ethics committee of King Faisal Specialist Hospital \& Research Center. Sixty consecutive symptomatic adult (18-60 years) NERD patients with persistent GERD symptoms occurring at least 3 times weekly for $>2$ months between June 2011 and June 2013 were prospectively analyzed. All patients provided written informed consent before being included in this study. The Patients were considered to have had NERD in a referring hospital, when no esophageal mucosal break was found during an upper gastrointestinal endoscopy, prior to medication. The patients who were treated with antisecretory drugs at the time of referral to our institution were asked to discontinue acid suppressive therapy at least 4 weeks before the endoscopic examination. During that period, patients were allowed to use an oral antacid on as needed basis for the relief of heartburn. Prior to MII-pH measurement, the endoscopy examination was repeated in our institution by 3 of our authors (FA, KA and HA) in those cases where the diagnosis of NERD was not confirmed at the referring hospital. Only refractory PPI patients with negative esophagogastroduodenoscopy were included in this study. Refractory PPI was defined as $>50 \%$ GERD symptoms persisting with a twice daily dose of PPI (20 mg b.i.d. omeprazole or esomeprazole, depending on referring physician preference) for at least 2 months prior to study inclusion. The severity of symptoms was rated by means of a validated questionnaire. ${ }^{10}$ Symptoms were graded as follows: $0=$ none; $1=$ mild/occasional, symptom could be ignored; $2=$ moderate/frequent, symptom could not be ignored; and $3=$ severe/constant, symptom influenced daily activities and/or sleep. For the inclusion criteria, asymptoms score of at least 2 was re- 
quired on PPI. The patients were advised to continue daily regular activity and to have a minimum of 3 standard meals during the study period. The patients were instructed not to consume any acidic beverages including apple, orange or lemon juice. Exclusion criteria included history of thoracic, esophageal or gastric surgery; esophageal varices; pregnancy; psychiatric illness; history of alcohol or drug abuse; or evidence of erosive esophagitis during the previous 6 months.

High-resolution manometry study was performed with a 4.2 $\mathrm{mm}$ outer diameter solid state assembly with 36 circumferential sensors spaced at 1-cm interval (Given Imaging, Los Angeles, CA, USA). Esophageal pressure topography data was analyzed using ManoView analysis software. High-resolution manometry was performed routinely prior to impedance-pH monitoring, both for the localization of lower esophageal sphincter and assessment of esophageal function to rule out any primary (achalasia, diffuse esophageal spasm or nutcrackers esophagus) or secondary (scleroderma, alcoholism or pseudoachalasia) severe esophageal motility disorder.

\section{Esophageal Multichannel Intraluminal Impedance-pH Monitoring}

Combined MII-pH monitoring was performed on an outpatient basis using an ambulatory, MII-pH system (Zephyr, Sandhill Scientific, Inc., Highlands Ranch, CO, USA). Only 60 NERD patients agreed to undergo MII-pH monitoring. Localization of the lower esophageal sphincter (LES) was made either by esophageal manometry (if indicated) or by air-flow sphincter locator which simplifies sphincter location when used in combination with ComforTec (Highlands Ranch, CO, USA) infused $\mathrm{pH}$ and $\mathrm{Z} / \mathrm{pH}$ probes. Combined MII-pH was performed with four impedance measuring sites located in the distal esophagus at $3,5,7$ and $9 \mathrm{~cm}$ and 2 impedance measuring sites in the proximal esophagus at 15 and $17 \mathrm{~cm}$ above the LES. Two antimony $\mathrm{pH}$ sensors were located $5 \mathrm{~cm}$ above and $10 \mathrm{~cm}$ below the LES allowing for simultaneous $\mathrm{pH}$ analysis in the distal esophagus and stomach. Patients were included in the study only when MII-pH data was recorded for at least 20 hours and properly downloaded. Gas reflux events without liquid (belches) were excluded from the analysis. Impedance-detected reflux episodes were classified as "acid" if the $\mathrm{pH}$ sensor recorded a decline in $\mathrm{pH}$ below 4 or as "non-acid" if the $\mathrm{pH}$ remained above 4 during bolus presence time in the esophagus. The group of non-acid reflux episodes included reflux classified in other publications as "weakly acidic" or "weakly alkaline." We preferred the term "acid" versus "non- acid," as these words provided better contrast in the implication and therapeutic approach from the gastroesophageal perspective. The following parameters were obtained from MII-pH recordings: total number of proximal and distal esophageal refluxes (acid, non-acid and total), DeMeester score, percent bolus exposure time (BET; acid, non-acid and total), percent distal EAET (acid, non-acid and total) and esophageal bolus clearance time (BCT; in seconds). The first parameter of MII-pH assessment was BET, defined as the sum of the duration of all reflux episodes (regardless of $\mathrm{pH}$ ) divided by the time monitored. The BET was considered pathological at times of $>1.4 \%$. ${ }^{11}$ The PPI refractory NERD patients were divided on the basis of BET, when the BET in 24 hours was $>1.4 \%$, the patients were classified in MII-pH positive $(+)$ group. The patients were placed in MII-pH negative $(-)$ group, if their BET was $<1.4 \%$. Total BCT was defined as the time, in seconds, from a $50 \%$ drop in impedance until recovery and above $(5 \mathrm{~cm}$ above LES). Total BCT of refluxate was considered abnormal if it lasted $>15$ seconds. EAET was defined as the percentage of time in which the distal esophageal $\mathrm{pH}$ was less than 4 over a 24 hour-period. In patients receiving PPI therapy twice daily, normal distal EAET was defined as an esophageal $\mathrm{pH}<4.0$ for $<1.5 \%$ of times spent upright and $<0.5 \%$ of time spent in the recumbent position (average $<1.3 \%$ ). The upper limit of normal esophageal reflux episodes over 24 hours for acid-suppressed patients was demarcated as 48 hours for distal and 14 for proximal reflux.

\section{Esophagogastroduodenoscopy}

All patients underwent upper gastrointestinal endoscopic examination and had no visible mucosal breaks in the distal esophageal epithelium (i.e., NERD). Hiatal hernia was considered to be present when the distance between the gastroesophageal (GE) junction and the diaphragmatic impression was $>2 \mathrm{~cm}$ upon endoscope withdrawal; particular attention was paid to the GE junction. Esophageal biopsies were not routinely performed in the absence of additional complaint of dysphagia or visual abnormalities suggestive of eosinophilic esophagitis.

\section{Reflux and Symptoms Association}

A symptom was considered associated with reflux if a reflux episode was detected 2 minutes prior to symptom onset. Heartburn, regurgitation and chest pain were considered typical GERD symptoms, whereas pulmonary (cough and asthma) and ear, nose and throat (ENT) symptoms (sore throat and hoarseness of voice) were considered atypical symptoms. Symptom in- 
dex (SI) was defined as the number of symptoms associated with reflux divided by the total number of symptoms. A positive SI was declared if $\geq 50 \%$ symptoms were associated with reflux. $\mathrm{SAP}$ was calculated by dividing 24 hours $\mathrm{pH}$ data into 2-minute segments. Each 2-minute segment was studied when a symptom occurred, whether or not reflux occurred. The probability of symptom distribution and reflux episodes in 2 minute-window was then calculated to determine if it could have occurred by chance $\left(X^{2}\right.$ test $)$; SAP $=1-p . \mathrm{SAP}$ was considered positive if $>$ $95 \%$. The SAP and SI were calculated on behalf of each typical or atypical GERD symptom separately for acid and non-acid refluxes. The patients with normal BET $(<1.4 \%)$ and positive symptoms association for either acid and/or non-acid reflux are defined as Hypersensitive esophagus. The patients with normal BET $(<1.4 \%)$ and negative symptoms association are categorized as functional heartburn.

\section{Statistical Methods}

Data were analyzed using IBM SPSS Statistic 20 software (IBM, Armonk, NY, USA). Kolmogorov-Smirnov test and Shapuro-Wilk test were used to test the normality of variables.
To determine the significant differences between means of variables, Kruskal Wallis Test with post hoc test was computed for variables with non-normal distributions. For continuous variables with normal distribution, independent sample $t$ test was established, and Pearson's Chi-square for categorical variables. $P$-value $<0.05$ was considered statistically significant.

\section{Results}

A total of 60 consecutive PPI-refractory NERD patients met inclusion criteria and entered the study, including 28 males and 32 females with a mean age of 45 years (range, 24-68 years). No significant difference was found concerning age and gender between the various groups. The average total duration of analysis of all patients was 21.98 hours. Mean body mass index for MII-pH $(+)$ NERD patients was higher $(30 \pm 7.19)$ than the MII-pH $(-)$ NERD $(26.53 \pm 5.02 ; P=0.050)$. The prevalence of hiatus hernia was noted in 32 patients $(53.3 \%)$, among them 17 had MII-pH (+) NERD and 15 had MII-pH ( - ) NERD $(P=0.625$; Table 1$)$. Chest pain and non-specific symptoms were more common in the MII-pH (-) NERD

Table 1. Demographic and Clinical Characteristics of Proton Pump Inhibitor Refractory Non-erosive Reflux Disease Patients in Multichannel Intraluminal Impedance-pH Positive (Bolus Exposure Time $>1.4 \%$ ) and Multichannel Intraluminal Impedance-pH Negative (Bolus Exposure Time $<1.4 \%$ ) Groups

\begin{tabular}{|c|c|c|c|c|}
\hline Basic characteristics & $\begin{array}{l}\text { Total NERD patients } \\
\qquad(\mathrm{N}=60)\end{array}$ & $\begin{array}{l}\text { pH-impedance positive NERD } \\
\quad(\text { BET }>1.4 \%, \mathrm{n}=32)\end{array}$ & $\begin{array}{l}\mathrm{pH} \text {-impedance negative NERD } \\
(\mathrm{BET}<1.4 \%, \mathrm{n}=28)\end{array}$ & $P$-value \\
\hline Age $($ mean $\pm \mathrm{SD}, \mathrm{yr})$ & $45.42 \pm 12.54$ & $46.45 \pm 13.98$ & $44.15 \pm 10.65$ & 0.721 \\
\hline $\operatorname{Sex}(M: F)$ & $32: 28$ & $18: 15$ & $14: 13$ & 0.805 \\
\hline $\mathrm{BMI}($ mean $\pm \mathrm{SD})$ & $29.34 \pm 6.30$ & $30 \pm 7.19$ & $26.53 \pm 5.02$ & 0.050 \\
\hline Hiatus hernia by endoscopy (n [\%]) & $32(53.33)$ & $17(53.2)$ & $\begin{array}{c}15(46.8) \\
(\mathrm{HE}=10, \mathrm{FH}=5)\end{array}$ & 0.625 \\
\hline $\begin{array}{l}\text { Mean pH-impedance } \\
\text { analysis duration }(\mathrm{hr})\end{array}$ & 21.98 & 21.74 & 22.28 & 0.220 \\
\hline DeMeester score $($ mean $\pm \mathrm{SD})$ & $3.20 \pm 4.47$ & $3.38 \pm 4.17$ & $2.97 \pm 4.88$ & 0.207 \\
\hline Mean GERD symptoms duration (mo) & 50.71 & 50.5 & 51.96 & 1.000 \\
\hline Total GERD symptoms (n [\%]) & $46 / 60(77)$ & $26 / 32(81)$ & $20 / 28(71)$ & 0.061 \\
\hline \multicolumn{5}{|l|}{ Typical symptoms } \\
\hline Heartburn & $41 / 46(89)$ & $23 / 26(88)$ & $18 / 20(90)$ & 0.073 \\
\hline Regurgitation & $30 / 46(65)$ & $18 / 26(70)$ & $15 / 20(75)$ & 0.105 \\
\hline Chest pain & $18 / 46(39)$ & $6 / 26(23)$ & $12 / 20(60)$ & 0.017 \\
\hline \multicolumn{5}{|l|}{ Atypical symptoms (n [\%]) } \\
\hline Pulmonary & $15 / 46(33)$ & $8 / 26(31)$ & $7 / 20(35)$ & 0.579 \\
\hline ENT & $11 / 46(24)$ & $6 / 26(23)$ & $5 / 20(25)$ & 0.745 \\
\hline Non-specific & $18 / 46(39)$ & $6 / 26(23)$ & $12 / 20(60)$ & 0.011 \\
\hline
\end{tabular}

NERD, non-erosive reflux disease; BET, bolus exposure time; BMI, body mass index; GERD, gastroesophageal reflux disease; ENT, ear, nose and throat; FH, functional heartburn; HE, hypersensitive esophagus. 
Table 2. Sub-classification of Proton Pump Inhibitor Refractory Non-erosive Reflux Disease Patients With Frequency of Acid and Non-acid Refluxes

$\begin{array}{lccc}\text { Sub-classification of NERD } & \text { Total number of refractory NERD }(\mathrm{N}=60, \mathrm{n}[\%]) & \text { Mean non-acid refluxes }(\%) & \text { Mean acid refluxes }(\%) \\ \text { MII-pH positive NERD } & 32(53) & 81 & 19 \\ \text { MII-pH negative NERD } & 28(47) & 80 & 20 \\ \text { Functional heartburn } & 15(25) & 92 & 8 \\ \text { Hypersensitive esophagus } & 13(22) & 70 & 30\end{array}$

NERD, non-erosive reflux disease; MII-pH, multichannel intraluminal impedance-pH.

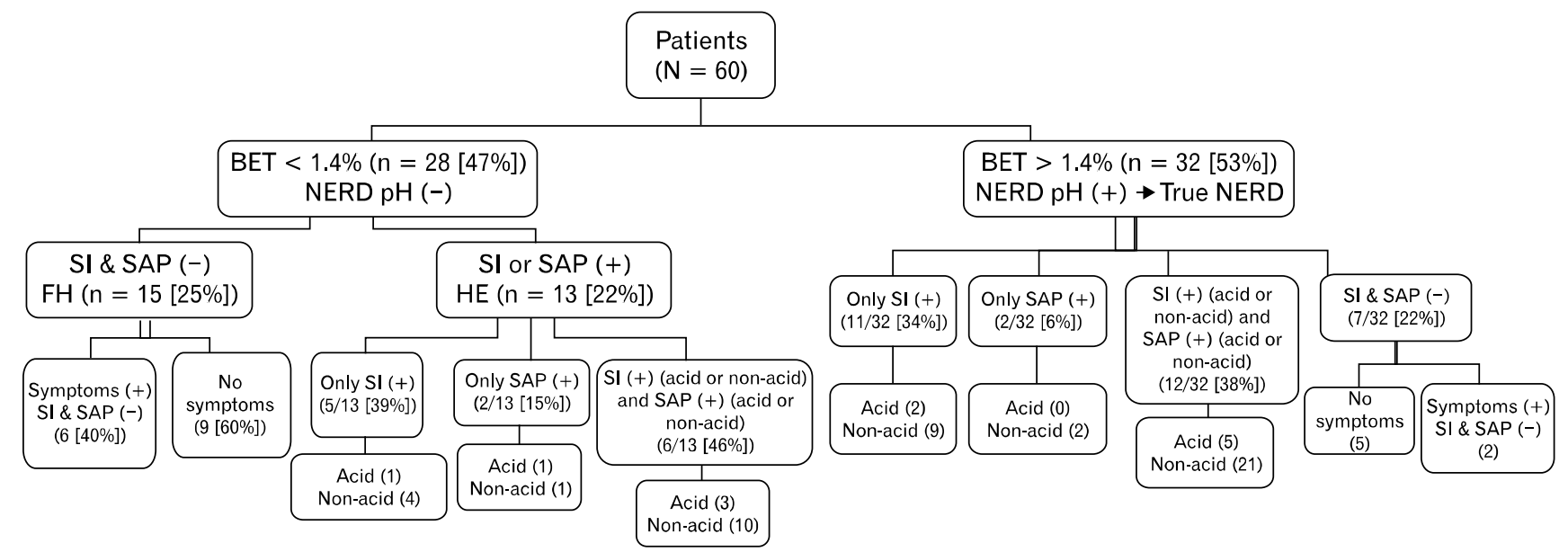

Figure 1. Division of proton pump inhibitor-refractory non-erosive reflux disease (NERD) patients on the basis of bolus exposure time (BET) and reflux symptoms association (symptom index $[\mathrm{SI}]$ and symptom associated probability $[\mathrm{SAP}]$ ).

group as compared to MII-pH $(+) \operatorname{NERD}$ group $(P=0.017)$. Non-specific symptoms (throat pain, epigastric pain, belching, chest tightness, palpitation, sweating and vomiting) were reported by 18 patients (18/46 [39\%]), the majority (60\%) of which $(\mathrm{n}=12)$ being in the MII-pH $(-)$ NERD group $(P=$ 0.011; Table 1). The refluxes in refractory PPI patients were mainly non-acid ( $>80 \%$ ), whether MII-pH-impedance results were positive or negative (Table 2 ).

\section{Sub-classification of Proton Pump Inhibitor Refractory Non-erosive Reflux Disease on the Basis of Symptom Reflux Association}

Thirty-two (53.3\%) patients were diagnosed as MII-pH $(+)$ NERD (true NERD). Although six out of 32 (19\%) patients had $<48$ total distal refluxes, their BET was $>1.4 \%$ and they were therefore considered as MII-pH $(+)$ NERD based on their higher than normal BET. Twenty-eight (47\%) patients had a BET $>1.4 \%$ and $>48$ distal GE refluxes. The significant proximal migration of reflux (15 $\mathrm{cm}$ above LES) was noted in 16/60 (27\%) patients, where the upper limit of normal proximal esophageal refluxes in our series was $<14$ refluxes in 24 hours. All patients who had $>14$ proximal refluxes had a BET $>1.4 \%$. Among 28 patients (47\%) with normal MII-pH recording ([-] NERD), 15 (25\%) had a negative SI and SAP and were diagnosed with $\mathrm{FH}$, whereas $13(22 \%)$ had (+) SI or SAP and were identified with HE. During 24 hour MII-pH monitoring, 46 (76.66\%) patients reported either typical or atypical GERD symptoms, while 14 patients (23.3\%) did not report any symptoms and eight reported symptoms but their SI or SAP was not significantly high. Regurgitation was the most common symptom reported by 41/46 (89\%) patients but only 15 had SI $(+)$ and $10 \mathrm{SAP}(+)$, followed by heartburn in 30/46 (65\%) patients (11 SI $[+]$ and $5 \mathrm{SAP}[+])$ and chest pain by 18/46 $(39 \%)$ subjects $(2 \mathrm{SI}[+], 2 \mathrm{SAP}[+])$. The patients that reported normal BET with negative SI and SAP, were diagnosed with FH. Six patients (40\%) from the FH still had GER symptoms but their SI and SAP were not significant. In the $\mathrm{HE}(\mathrm{n}=$ 13) group, 5 patients were $\mathrm{SI}(+), 2$ were $\mathrm{SAP}(+)$ and 6 were both SAP and SI $(+)$. The total number of non-acid and acid SI or SAP was 47 and 12, respectively. Detail further classification 
Table 3. Multichannel Intraluminal Impedance-pH Parameters in Proton Pump Inhibitory Refractory Non-erosive Reflux Disease Patients and Their Association With Hypersensitive Esophagus and Functional Heartburn

\begin{tabular}{|c|c|c|c|c|c|c|c|}
\hline \multirow{2}{*}{ MII-pH parameters } & \multirow{2}{*}{$\begin{array}{c}\text { Total } \\
\text { Patients } \\
(\mathrm{N}=60)\end{array}$} & \multirow{2}{*}{$\begin{array}{c}\text { NERD } \\
\text { MII-pH }(+) \\
(\mathrm{n}=32)\end{array}$} & \multicolumn{2}{|c|}{$\begin{array}{l}\text { NERD MII-pH }\left(^{-}\right) \\
\quad(\mathrm{n}=28)\end{array}$} & \multirow{2}{*}{$\begin{array}{c}\text { NERD } \\
\text { MII-pH (+) } \\
\text { vs. FH } \\
(P \text {-value })\end{array}$} & \multirow{2}{*}{$\begin{array}{c}\text { NERD } \\
\text { MII-pH (+) } \\
\text { vs. HE } \\
(P \text {-value })\end{array}$} & \multirow{2}{*}{$\begin{array}{c}\text { FH vs. } \mathrm{HF} \\
(P \text {-value })\end{array}$} \\
\hline & & & $\begin{array}{c}\mathrm{FH} \\
(\mathrm{n}=15)\end{array}$ & $\begin{array}{c}\mathrm{HE} \\
(\mathrm{n}=13)\end{array}$ & & & \\
\hline \multicolumn{8}{|l|}{ Distal esophageal refluxes } \\
\hline Acidic & 10.00 & 13.91 & 3.00 & 7.00 & 0.060 & 0.198 & 0.058 \\
\hline Non-acidic & 43.32 & 62.45 & 17.00 & 22.27 & $<0.001$ & $<0.001$ & 0.193 \\
\hline Total refluxes in $24 \mathrm{hr}(<48)$ & 53.32 & 76.36 & 20.00 & 29.27 & $<0.001$ & $<0.001$ & 0.086 \\
\hline \multicolumn{8}{|l|}{ Proximal esophageal refluxes } \\
\hline Acidic & 6.58 & 9.64 & 1.58 & 3.87 & 0.024 & 0.130 & 0.180 \\
\hline Non-acidic & 22.25 & 33.72 & 7.92 & 8.47 & $<0.001$ & $<0.001$ & 0.666 \\
\hline Total refluxes in $24 \mathrm{hr}(<14)$ & 28.83 & 43.36 & 9.50 & 12.34 & $<0.001$ & $<0.001$ & 0.287 \\
\hline \multicolumn{8}{|l|}{ EAET } \\
\hline Upright $<1.6 \%$ & 0.52 & 1.19 & 0.21 & 0.47 & 0.081 & 0.266 & 0.055 \\
\hline Recumbent $<0.5 \%$ & 0.32 & 0.54 & 0.08 & 1.23 & 0.247 & 0.372 & 0.374 \\
\hline All reflux $\%$ EAET $(<1.3 \%)$ & 0.84 & 0.73 & 0.29 & 1.70 & 0.036 & 0.654 & 0.128 \\
\hline \multicolumn{8}{|l|}{$\% \mathrm{BET}$} \\
\hline Acidic & 0.28 & 0.15 & 0.08 & 0.20 & 0.025 & 0.015 & 0.014 \\
\hline Non-acidic & 1.89 & 2.89 & 0.43 & 0.52 & 0.005 & $<0.001$ & 0.187 \\
\hline All reflux \% BET $(<1.4)$ & 2.17 & 3.04 & 0.51 & 0.72 & $<0.001$ & $<0.001$ & 0.046 \\
\hline Bolus clearance time $(<15 \mathrm{sec})$ & 16.08 & 21.19 & 11.25 & 10.53 & 0.032 & $<0.001$ & 0.242 \\
\hline
\end{tabular}

MII-pH, multichannel intraluminal impedance-pH; NERD, non-erosive reflux disease; FH, functional heartburn; HE, hypersensitive esophagus; EAET, esophageal acid exposure time; BET, bolus exposure time.

$P \leq 0.05$ considered significant.

(on the basis of SI and SAP distribution) of each NERD sub-class is shown in Figure 1.

\section{Comparison of Acid and Non-acid Reflux in Each Non-erosive Reflux Disease Sub-group}

In all PPI-refractory NERD patients, the average number of total distal acid refluxes was 10 (7 in erect and 3 in supine positions) and non-acid reflux was 43 (34 upright and 9 supine). Although, the number of distal and proximal acid refluxes were higher in $\mathrm{pH}(+)$ NERD patients than $\mathrm{FH}$ and $\mathrm{HE}$, the difference was not statistically significant. However when the total number of non-acid refluxes were compared between $\mathrm{FH}$ and $\mathrm{pH}(+) \mathrm{NERD}$ or $\mathrm{HE}$ and $\mathrm{pH}(+) \mathrm{NERD}$, the number of non-acidic refluxes were much higher in $\mathrm{pH}(+) \mathrm{NERD}$ than $\mathrm{FH}$ and $\mathrm{HE}$ group and the difference was statistically significant $(P<0.001)$. Mean total (upright and recumbent) EAET was on the lower normal side $(0.84 \%)$; however, despite the use of a PPI in six cases (10\%), EAET was significantly higher than normal $(<1.3 \%)$. Furthermore, BCT showed a similar trend to BET. The details of correlations between true NERD, FH, HE

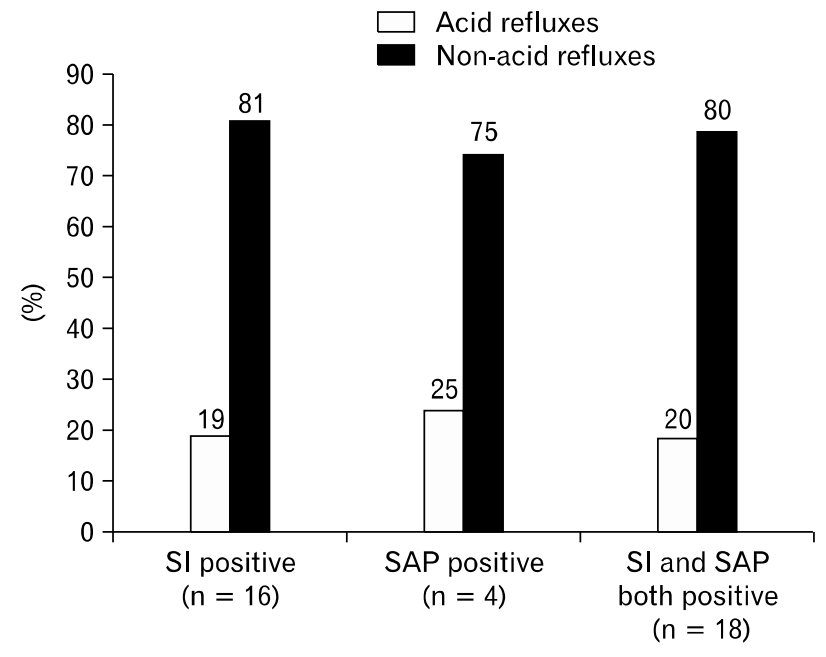

Figure 2. Nature (acid and non-acid) of reflux symptoms in 38 symptom index/symptom associated probability (SI/SAP) positive proton pump inhibitor-refractory non-erosive reflux disease patients. 
with BET, BCT, EAET and distal and proximal acid and non-acid reflux are summarized in Table 3.

\section{Nature of the Reflux Symptoms in Symptom Index/Symptom Association Probability Positive Patients}

Only 38/60 (63\%) patients reported significant SI or SAP parameters during an average 22 hours of MII-pH recording. On the assessment of the nature of symptoms in all 38 symptomatic patients, $74 \%$ showed symptoms secondary to non-acid reflux, $10 \%$ due to acid reflux and $16 \%$ due to both acid and non-acid reflux. In order to assess the frequency of symptom reflux association and evaluate the reflux nature, we divided these patients into 3 groups: (1) 16 patients (42\%) were only SI (+), (2) 4 patients (11\%) were only SAP (+) and (3) 18 patients $(47 \%)$ were both SI and SAP $(+)$. Assessment of reflux nature in the SI $(+)$ group showed that the majority of patients (81\%) were non-acid-related SI $(+)$, while $19 \%$ were acid-related SI $(+)$. The nature of reflux and comparison of all 3 groups (1-3) are shown in Figure 2.

\section{Discussion}

In order to study the role of MII-pH monitoring in PPI-refractory NERD, the upper limits of normal distal/proximal reflux and the normal limits of BET on PPI therapy must be discussed first. Tutuian et $\mathrm{al}^{12}$ first described the upper limit of normal GER values on PPI. They proposed normal values of $<42$ for distal refluxes and $<14$ for proximal refluxes and suggested the total number of reflux episodes diminished on PPI, which predominantly reduced acid reflux but not the number of non-acid refluxes. A very recently published study by Zerbib et $\mathrm{al}^{13}$ described normal values in 46 healthy subjects and in subjects taking PPI for 2 weeks. On PPI therapy, subjects had a median value of 21 for distal refluxes, 2 for proximal refluxes, BET of $0.6 \%$ and EAET of $0.0 \%$. Their results confirmed that PPI therapy not only changed the chemical composition of the refluxate but also significantly reduced the total number of refluxes and BET. ${ }^{12,13}$ In contrast, other investigators demonstrated that PPI primarily changed the $\mathrm{pH}$ of the refluxate without affecting the total number of reflux episodes. ${ }^{14,15}$ Due to these discrepancies, there has been no consensus established on the upper limit of normal mean values in PPI-refractory NERD patients. The factors which affect the standardization of normal values in PPI-refractory NERD cases are variable PPI doses $(20-40 \mathrm{mg})$, fre- quency (once or twice daily), timing of drug intake (before or after meals) and PPI compliance during the previous 7 days of MII-pH monitoring. In addition, the differences and variations in dietary habits, body weight and postural position over 24 hours, hiatus hernia, Helicobacter pylori infection and delayed gastric emptying have made adaptation of normal values in PPI-refractory NERD more difficult. In view of all these variables, it is clear that standardization of MII-pH analysis in PPI-refractory NERD patients requires further investigation. However, in agreement with previous studies in NERD patients on PPI therapy, ${ }^{12-14}$ we used 48 for the upper limit of distal GER, 14 for proximal GER, $1.4 \%$ for BET and $1.5 \%$ for EAET.

There are various ways to classify refractory NERD based on symptom association and reflux parameters, including BET. The contribution of MII-pH monitoring in identifying the subgroup of refractory NERD patients with $\mathrm{HE}$ and $\mathrm{FH}$ to non-acid reflux is clinically important because it spares $\mathrm{FH} \mathrm{pa-}$ tients' inefficient and protracted courses of acid suppression therapy over years. A larger European study ${ }^{16}$ assessed MII-pH in 80 NERD patients on PPI and restricted the diagnosis of $\mathrm{FH}$ in one-third of cases, comparable to our series. However, an abnormal number of distal refluxes (normal $<45$ ) were reported in $56 \%$ and proximal refluxes (normal $<32$ ) in $41 \%$, although we found abnormal distal refluxes (normal < 48) in $43 \%$ and proximal (normal < 14) in $27 \%$ of patients; this difference was due to lower reference values of proximal refluxes in our series. The numbers of pathological distal refluxes were different between studies because the upper normal values fluctuated in each study.

Pathological findings on MII-pH monitoring were identified in almost half (53\%) of our NERD patients based on BET, although lesser number of abnormal patients (43\%) was recognized when the abnormality was detected on the basis of number of distal refluxes. In agreement with other studies, ${ }^{17,18}$ we also believe that in PPI-refractory NERD patients BET values are more reliable than the number of distal refluxes because BET accounts for the total number and duration of acid and non-acid refluxes. In our study, the mean total EAET was $0.84 \%$ on 20 mg omeprazole twice daily. In the past, Kuo and Castell ${ }^{19}$ reported $1.10 \%$ on $20 \mathrm{mg}$ omeprazole twice daily, much higher than the median value of "0\%" reported recently. ${ }^{13}$ This discrepancy is probably related to the higher dose of PPI ( $40 \mathrm{mg}$ b.i.d. esomeprazole) used in the latter study. We also reported that $10 \%$ patients had pathological EAET despite the use of PPI which was possibly related with the non-compliance and unscheduled timing of the treatment. We propose that in refractory PPI pa- 
tients the significance of a higher EAET is merely to confirm a patient's non-compliance with treatment because symptoms are mainly secondary to non-acid reflux.

By using a stepwise diagnostic approach in the present study, $63 \%$ of symptomatic patients reported either positive SI or SAP, in whom majority of reflux symptoms were induced by non-acid reflux which would have been found negative with only conventional, non-MII pH-monitoring. Mainie et $\mathrm{al}^{20}$ demonstrated that $48 \%$ of their patients on PPI were SI $(+)$ (37\% non-acid and $11 \%$ acid), while the remaining $52 \%$ had no association between reflux and symptoms. Another previous study reported MII-pH monitoring in a group of 71 patients on PPI and found that $36 \%$ of symptomatic patients were $\mathrm{SAP}(+)(16 \%$ non-acid, $5 \%$ acid and $15 \%$ combination of both). ${ }^{21}$ In agreement with both of these studies, we found that the majority of refluxes in PPI-refractory NERD patients were non-acid. Slaughter et $\mathrm{al}^{22}$ concluded that SI/SAP indices could be over-interpreted unless patients with GERD refractory to PPI therapy had high rates of reflux. Others also agreed that tests like SI or SAP are preferable but sub-optimal in predicting response to high-dose PPI therapy. $^{23}$

Unfortunately there were some limitations to our study that should be acknowledged even though data was collected prospectively. In particular, the patient's compliance before the procedure and the timing of PPI administration were not considered in the results. Additionally, it would have been better if the detail parameters of high-resolution manometry could have been evaluated and included in the results on all patients in order to better understand the pathophysiology of NERD.

In conclusion, the results from this PPI-refractory NERD study showed that the majority of symptomatic patients continued to have significant non-acid reflux. Moreover MII-pH demonstrated to offer the assessment of the relationship between symptoms and reflux that distinguishes between $\mathrm{FH}$ and pathological NERD. This is clinically useful because patients with functional heartburn should not be prescribed with PPIs. However our current knowledge of this complex sub-classification of NERD is incomplete due to controversial cut-off reference values of PPI and uncertainties about over-interpretation of SI and SAP parameters. The unpredictable therapeutic response to these challenging sub-groups of NERD needs to be further evaluated with prospective outcome studies for the best medical or surgical approach.

\section{Acknowledgements}

The authors would like to thank Mr Zaid Al-Yami for his contribution and help in collecting the patient's data and Mrs Alaine Balbutin for her involvement in compiling the statistical analysis and organizing tables and figures for this research project.

\section{References}

1. Fass R. Erosive esophagitis and nonerosive reflux disease (NERD): comparison of epidemiologic, physiologic, and therapeutic characteristics. J Clin Gastroenterol 2007;41:131-137.

2. Scarpignato C. Poor effectiveness of proton pump inhibitors in nonerosive reflux disease: the truth in the end! Neurogastroenterol Motil 2012;24:697-704.

3. Gupta N, Inadomi JM, Sharma P. Perception about gastroesophageal reflux disease (GERD) and its impact on daily life in the general population: results from a large population based AGA survey. Gastroenterology 2012;142(suppl 1):S411.

4. Dean BB, Gano AD Jr, Knight K, Ofman JJ, Fass R. Effectiveness of proton pump inhibitors in nonerosive reflux disease. Clin Gastroenterol Hepatol 2004;2:656-664.

5. Vela MF, Camacho-Lobato L, Srinivasan R, Tutuian R, Katz PO, Castell DO. Simultaneous intraesophagealimpedance and $\mathrm{pH}$ measurement of acid and non-acid reflux: effect of omeprazole. Gastroenterology 2001;120:1599-1606.

6. Sifrim D, Castell D, Dent J, Kahrilas PJ. Gastro-esophageal reflux monitoring: review and consensus report on detection and definitions of acid, non-acid, and gas reflux. Gut 2004;53:1024-1031.

7. Savarino E, Zentilin P, Tutuian R, et al. The role of non-acid reflux in NERD - lessons learned from impedance-pH monitoring in 150 patients off therapy. Am J Gastroenterol 2008;103:2685-2693.

8. Johnston BT, Lewis SA, Collins JS, McFarland RJ, Love AH. Acid perception in gastro-oesophageal reflux disease is dependent on psychological factors. Scand J Gastroenterol 1995;30:1-5.

9. Clayton SB, Rife CC, Singh ER, Kalbfleisch JH, Castell DO. Twice-daily proton pump inhibitor therapy does not decrease the frequency of reflux episodes during nocturnal recumbency in patients with refractory GERD: analysis of 200 patients using multichannel intraluminal impedance-pH testing. Dis Esophagus 2012;25:682-686.

10. Pritchett JM, Aslam M, Slaughter JC, Ness RM, Garrett CG, Vaezi MF. Efficacy of esophageal impedance $/ \mathrm{pH}$ monitoring in patients with refractory gastroesophageal reflux disease, on and off therapy. Clin Gastroenterol Hepatol 2009; 7:743-748.

11. Tutuian R, Vela MF, Shay SS, Castell DO. Multichannel intraluminal impedance in esophageal function testing and gastroesophageal reflux monitoring. J Clin Gastroenterol 2003;37:206-215.

12. Tutuian R, Mainie I, Agrawal A,Freeman J, Castell DO. Normal values for ambulatory 24-hour combined impedance-pH monitoring on acid suppressive therapy. Gastroenterology 2006;130(suppl 2):A171.

13. Zerbib F, Roman S, Bruley Des Varannes S, et al. Normal values of pharyngeal and esophageal 24-hour $\mathrm{pH}$ impedance in individuals on and off therapy and interobserver reproducibility. Clin Gastroenterol 
Hepatol 2013;11:366-372.

14. Frazzoni M, Savarino E, Manno M, et al. Reflux patterns in patients with short-segment Barrett's oesophagus: a study using impedance$\mathrm{pH}$ monitoring off and on proton pump inhibitor therapy. Aliment Pharmacol Ther 2009;30:508-515.

15. Tamhankar AP, Peters JH, Portale G, et al. Omeprazole does not reduce gastroesophageal reflux: new insights using multichannel intraluminal impedance technology. J Gastrointest Surg 2004;8:890-897.

16. Frazzoni M, Conigliaro R, Mirante VG, Melotti G. The added value of quantitative analysis of on-therapy impedance- $\mathrm{pH}$ parameters in distinguishing refractory non-erosive reflux disease from functional heartburn. Neurogastroenterol Motil 2012;24:141-146, e87.

17. Sinn DH, Kim BJ, Son HJ, Kim JJ, Rhee JC, Rhee PL. Pathological bolus exposure may define gastro-esophageal reflux better than pathological acid exposure in patients with globus. Hepatogastroenterology 2012;59:317-320.

18. Kim BJ, Choi SC, Kim JJ, Rhee JC, Rhee PL. Pathological bolusexposure plays a significant role in eliciting non-cardiac chest pain. J
Gastroenterol Hepatol 2010;25:1855-1860.

19. Kuo B, Castell DO. Optimal dosing of omeprazole $40 \mathrm{mg}$ daily: effects on gastric and esophageal $\mathrm{pH}$ and serum gastrin in healthy controls. Am J Gastroenterol 1996;91:1532-1538.

20. Mainie I, Tutuian R, Shay S, et al. Acid and non-acid reflux in patients with persistent symptoms despite acid suppressive therapy: a multicentre study using combined ambulatory impedance- $\mathrm{pH}$ monitoring. Gut 2006;55:1398-1402.

21. Zerbib F, Roman S, Ropert A,Chaput U, et al. Esophageal pH-impedance monitoring and symptom analysis in GERD: a study in patients off and on therapy. Am J Gastroenterol 2006;101:1956-1963.

22. Slaughter JC, Goutte M, Rymer JA, et al. Caution about over interpretation of symptom indexes in reflux monitoring for refractory gastroesophageal reflux disease. Clin Gastroenterol Hepatol 2011;9:868-874.

23. Taghavi SA, Ghasedi M, Saberi-Firoozi M, et al. Symptom association probability and symptom sensitivity index: preferable but still suboptimal predictors of response to high dose omeprazole. Gut 2005; 54:1067-1071. 